\title{
Optimization of THz diffractive optical elements thickness
}

\author{
M. Surma, ${ }^{* 1}$ I. Ducin, ${ }^{1}$ M. Sypek, ${ }^{1}$ P. Zagrajek, ${ }^{2}$ and A. Siemion ${ }^{1 *}$ \\ ${ }^{1}$ Faculty of Physics, Warsaw University of Technology, Koszykowa 75, 00-662 Warsaw, Poland \\ ${ }^{2}$ Institute of Optoelectronics, Military University of Technology, gen. Urbanowicza 2, 00-908 Warsaw, Poland
}

Received December 21, 2018; accepted December 29, 2018; published December 31, 2018

\begin{abstract}
Diffractive optical elements (DOEs) are strictly related to the design wavelength since they must introduce a particular phase delay of the wavefront propagating through the structure. Mostly, the attenuation of the material is not considered. In this article we propose to optimize the thickness of a DOE by reducing not only introduced phase retardation but also attenuation. The efficiency of DOEs is determined by the method of coding phase distribution and can be easily measured by using diffraction orders of a corresponding diffraction grating. Here, we analyze binary phase diffraction gratings with assumed attenuation.
\end{abstract}

Diffractive optical elements (DOEs) provide lightweight and compact replacement for refractive ones. In the terahertz $(\mathrm{THz})$ regime, understood as electromagnetic waves from $100 \mathrm{GHz}$ and $10 \mathrm{THz}$ range [1-2], those features may play a critical role due to a relatively long wavelength of the mentioned waves. Generally, DOEs introduce a particular phase shift of the incident beam to form desired phase distribution when leaving the structure. Such an approach requires defining a particular wavelength $\lambda$ and corresponding to it the refractive index $n$ of the used material to calculate the proper thickness of the structure (assuming binary structure surrounded by air):

$$
h_{\max }=\frac{\lambda \cdot \varphi_{\max }}{2 \pi \cdot(n-1)} .
$$

This letter concentrates on efficiency of diffractive $\mathrm{THz}$ elements based on paper, however other materials can also be used [3]. Paper, possessing a non-negligible value of absorption coefficient for $\mathrm{THz}$ radiation and being highly accessible and easy in manufacturing, is an ideal material for the purpose of examining the influence of absorption on efficiency of designed diffractive optical elements [45].

The analysis of diffraction efficiencies of binary phase diffractive gratings is carried out since it corresponds to the efficiency of DOEs designed with the same phase coding method. Nevertheless, the application of $\mathrm{THz}$ gratings is also noticeable. They can be used as $\mathrm{THz}$ couplers [6], for measurements of the refractive index of a material [7], as polarizers [8], for controlling the surface beam profile of lasers [9] and many more.

\footnotetext{
*E-mail: 01103804@pw.edu.pl; agnieszka@if.pw.edu.pl
}

Conducted examination will allow to optimize the process of design of diffractive elements such as lenses (focusing, forming optical vortices, producing different focusing patterns or structured beams), structures generating diffraction-less beams, beam shaping elements or holograms. Accounting for material parameters may be necessary for certain regimes of electromagnetic waves for which materials introducing a phase change possesses also high absorption coefficients (the same problem relates to materials used for UV [10-11]).

To simplify the process of investigation, as representative structure a binary diffractive phase grating was selected, with a fill factor of $50 \%$ and a $1 \mathrm{~cm}$ period. According to theory such an element introducing a phase change of $\pi$ should diffract directly incoming light into odd orders of diffraction [12]. For perfect phase retardation, the $0^{\text {th }}$ order is not present, it starts to appear in the case when the thickness of the structure does not introduce a phase shift of $\pi$ [13-14]. The $-1^{\text {st }}$ and $+1^{\text {st }}$ diffraction orders are equal and each collects $40.4 \%$ of the incoming energy. It should be noticed that the next visible orders are $-3^{\text {rd }}$ and $+3^{\text {rd }}$ with an efficiency of $4.5 \%$, and all higher orders collect about $10 \%$ of the incoming energy.

For such grating changes in thickness, and thus in absorption, will result in a change of diffraction efficiency (distribution of output intensity). The design wavelength was $1 \mathrm{~mm}$ which corresponded to $0.3 \mathrm{THz}$. The designed gratings were manufactured in a $3 \mathrm{D}$ printing technique in paper using an MCor Iris printer [15].

Prior to the design process was the determination of the material optical properties. Time Domain Spectroscopy (TDS - TeraView) was used for this task. The values of the refractive index and absorption coefficient were measured and, for paper, are equal to 1.39 and $1.7 \mathrm{~cm}^{-1}$, respectively. The analysis of the influence of glue on the refractive index was also already carried out [4]. Measurements were conducted in a chamber filled with dry air to eliminate the absorption peaks of water vapour. Such a procedure was used to determine material parameters of paper (like the refractive index and absorption coefficient).

Then, the manufactured gratings were measured in the experimental setup. It consisted of a $\mathrm{THz}$ source 
(Schottky diode emitting at $0.3 \mathrm{THz}$ ), evaluated grating, spherical diffractive lens (diameter and focal length of $300 \mathrm{~mm}$ [16]) and detector (frequency multiplier with Schottky diode) placed at the Fourier plane, shown in Fig. 1. The measurements had the form of 1D scans along $x$ axis corresponding to changes in intensity pattern induced by grating. It should be noted that the axis of diffraction orders in the Fourier plane is perpendicular to the openings in the grating and small rotation of the grating introduces differences in the scanned intensity of the $+1^{\text {st }}$ and $-1^{\text {st }}$ orders. Thus, the experiment was carried out with precision to minimize this effect.
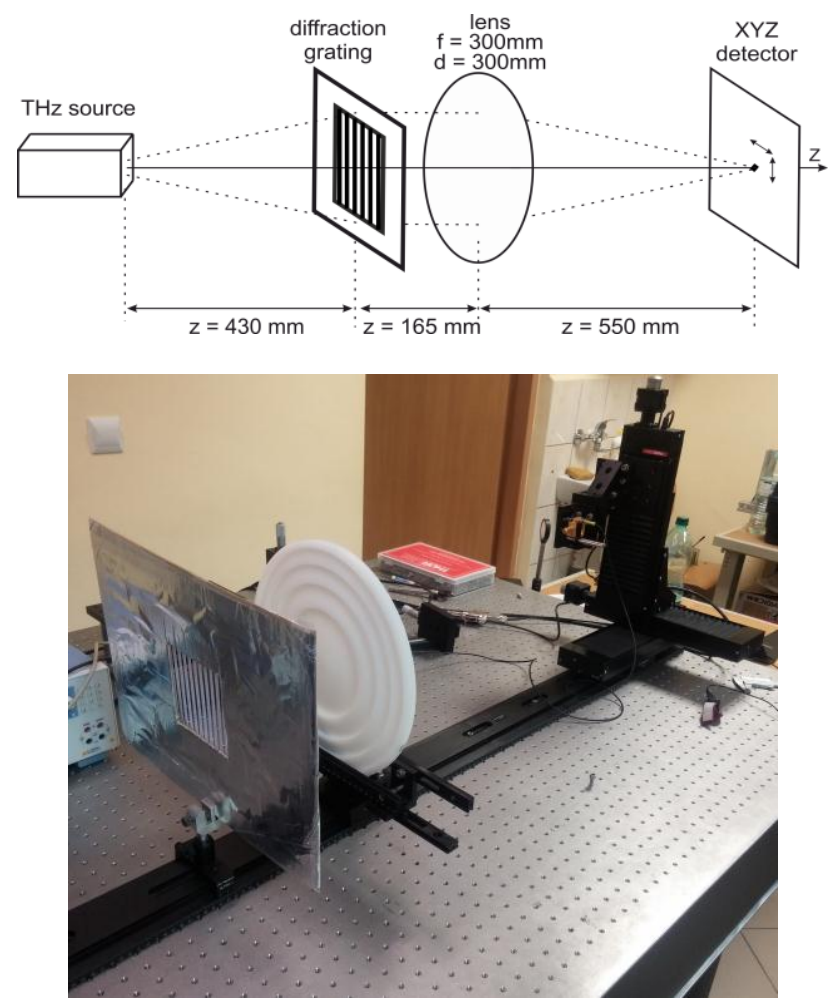

Fig. 1. Scheme of the experimental setup (upper) and photo of investigated element (lower).

Theoretically, the best structure should have the thickness of $h=1.28 \mathrm{~mm}$, however such a value could not be achieved due to limitations of structure fabrication (the thickness had to be a multiple of $0.103 \mathrm{~mm}$, which corresponds to one sheet of paper). A set of diffraction gratings having different thicknesses (from 5 to 13 sheets of paper) were designed and manufactured using a 3D paper printer. In Tab. 1, theoretically determined values of diffraction efficiency for binary phase gratings with different thicknesses are given. Then, normalized intensity for $1^{\text {st }}$ and $0^{\text {th }}$ diffraction orders is calculated and compared to the experimental results in Tab. 1.

It should be defined that the diffraction efficiency in $1^{\text {st }}$ order is described with the equation:

$$
\eta_{1}=4 \frac{\sin ^{2}\left(\frac{\varphi}{2}\right)}{\pi^{2}}
$$

while in the case of $0^{\text {th }}$ order it is:

$$
\eta_{0}=\cos ^{2}\left(\frac{\varphi}{2}\right)
$$

Theoretical intensity values consider attenuation and are calculated using Beer-Lambert's law. It can be seen that the maximum intensity in $1^{\text {st }}$ diffraction order is for the thickness corresponding to 8 paper layers, while the proper phase shift will be introduced by the structure having 13 sheets of paper.

Table 1: Theoretical calculations and experimental evaluation of the intensity in $0^{\text {th }}$ and $1^{\text {st }}$ diffraction orders of measured for paper grating

\begin{tabular}{|c|c|c|c|c|c|c|c|}
\hline & $\begin{array}{l}\text { No. of } \\
\text { layers }\end{array}$ & $\begin{array}{c}\text { Thickness } \\
{[\mathrm{mm}]}\end{array}$ & $\begin{array}{c}\text { Phase } \\
\text { reatrdation } \\
\text { [rad] }\end{array}$ & $\begin{array}{c}\text { Diffraction } \\
\text { efficiency } \\
{\text { (in } 1^{\text {st }}} \\
\text { order) }\end{array}$ & $\begin{array}{c}\text { Normalized } \\
\text { intensity in } \\
1^{\text {st }} \text { order } \\
\text { with } \\
\text { attenuation }\end{array}$ & $\begin{array}{c}\text { Normalized } \\
\text { intensity in } \\
0^{\text {th }} \text { order }\end{array}$ & $\begin{array}{l}1^{\text {st }} / 0^{\text {th }} \\
\text { order } \\
\text { ratio }\end{array}$ \\
\hline \multirow{9}{*}{ 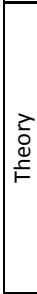 } & 5 & 0.52 & 1.26 & 0.14 & 0.82 & 1.000 & 0.2 \\
\hline & 6 & 0.62 & 1.51 & 0.19 & 0.93 & 0.680 & 0.4 \\
\hline & 7 & 0.72 & 1.77 & 0.24 & 0.99 & 0.435 & 0.6 \\
\hline & 8 & 0.82 & 2.02 & 0.29 & 1.00 & 0.257 & 1.0 \\
\hline & 9 & 0.93 & 2.27 & 0.33 & 0.96 & 0.135 & 1.9 \\
\hline & 10 & 1.03 & 2.52 & 0.37 & 0.89 & 0.059 & 4.0 \\
\hline & 11 & 1.13 & 2,78 & 0.39 & 0.80 & 0.018 & 11.9 \\
\hline & 12 & 1.24 & 3.03 & 0.4 & 0.69 & 0.001 & 127.0 \\
\hline & 13 & 1.34 & 3.28 & 0.4 & 0.58 & 0.002 & 83.0 \\
\hline \multirow{9}{*}{ 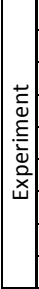 } & 5 & 0.52 & 1.26 & & 0.70 & 1 & 0.7 \\
\hline & 6 & 0.62 & 1.51 & & 0.90 & 1 & 0.9 \\
\hline & 7 & 0.72 & 1.77 & & 1.00 & 0.54 & 1.8 \\
\hline & 8 & 0.82 & 2.02 & & 1.00 & 0.29 & 3.5 \\
\hline & 9 & 0.93 & 2.27 & & 0.97 & 0.05 & 19.2 \\
\hline & 10 & 1.03 & 2.52 & & 0.69 & 0.04 & 18.8 \\
\hline & 11 & 1.13 & 2,78 & & 0.78 & 0.18 & 4.3 \\
\hline & 12 & 1.24 & 3.03 & & 0.73 & 0.36 & 2.1 \\
\hline & 13 & 1.34 & 3.28 & & 0.50 & 0.69 & 0.7 \\
\hline
\end{tabular}
with different thicknesses.

The theoretical calculations and experimental results correspond very well for the intensities compared in 1st diffraction order. However, in the case of $0^{\text {th }}$ diffraction order an increase of intensity values for greater thicknesses (11, 12 and 13 layers) is observed. It may result from the fact that the grating has no infinite transmittance, as for the theoretical case, and consists only of 10 periods, which introduces additional influence of the square aperture.

To compare these structures there are two parameters that should be considered - the intensity (related to energy) in $1^{\text {st }}$ diffraction order and - the intensity in $0^{\text {th }}$ order. The former determines the efficiency of a designed element, while the latter is related to unwanted background noise. It should be pointed out that the $0^{\text {th }}$ diffraction order in the case of optical elements corresponds to the radiation that was not bent, so this energy is distributed around the whole aperture area (in the case of plane wave illumination - uniformly). Thus, in the last column the ratio of intensity redirected into $1^{\text {st }}$ 
order to $0^{\text {th }}$ one was calculated. In experimental evaluation it is clear that the structure with a decreased thickness redirects more energy in $1^{\text {st }}$ order of diffraction and has lower noise due to a smaller value of energy in $0^{\text {th }}$ order.

As it can be seen in Tab. 1 from the theoretical calculations, the maximal amount of energy redirected into $1^{\text {st }}$ order is for the structure having 8 layers. It is also true for the experimental evaluation - the structure having 8 and also 7 layers has the maximal value of energy in $1^{\text {st }}$ order, but the one with 8 layers has a much lower value of $0^{\text {th }}$ order. It is worth noticing that the structure with 9 layers has a very similar amount of energy in $1^{\text {st }}$ order, but significantly smaller $0^{\text {th }}$ order peak. Thus, in such a case we decided to choose the structure with 9 layers as the best one.

Figure 2 shows intensity distributions registered by a scanning detector for different thicknesses of grating. $0^{\text {th }}$ order of diffraction is clearly visible, which should not be in the case for binary phase grating with a fill factor equal to $50 \%$ (with correct thickness introducing a proper phase shift). Even though the amount of energy in \pm 1 order of diffraction is relatively high for different thicknesses, it should be taken into account that the structure with a lowest $0^{\text {th }}$ order value will introduce the smallest unwanted background noise. Finally, the total efficiency of an optical element coded in such a way will be larger. It is important in the case of designing optical structures that do not have a fill factor equal to $50 \% \mathrm{n}$ and there the optimization of thickness can give good results.

Taking under consideration the information up to this point and the experimental data it is clearly visible that a 9-layer structure is the best (has best $1^{\text {st }}$ to $0^{\text {th }}$ order ratio and concurrently almost the highest value of efficiency in $1^{\text {st }}$ order).

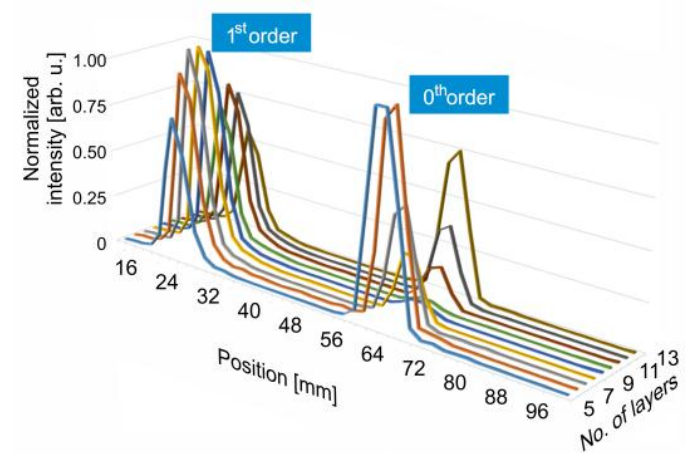

Fig. 2. Intensity in $1^{\text {st }}$ and $0^{\text {th }}$ diffraction orders in relation to sample thickness.

Concluding, the reduction of diffractive optical structure thickness can result in obtaining better total efficiency of the designed element in comparison with an unoptimized one, by increasing the signal-to-noise ratio (more energy redirected to $1^{\text {st }}$ order of diffraction and less energy forming noise - coming from $0^{\text {th }}$ order). Especially for structures made of materials with non-negligible value of absorption coefficient, it may be worth one's while to design a structure with a theoretically smaller diffractive efficiency, but, thanks to smaller attenuation, with noticeably higher energy in the appropriate orders of diffraction. Such information can be used for designing other diffractive elements such as lenses or holograms.

We have experimentally demonstrated that in the case of designing $\mathrm{THz}$ diffractive optical elements the presence of attenuation should be considered. Many materials used to manufacture $\mathrm{THz}$ optics have a non-negligible value of absorption coefficient, and the ones that have good transparency, mostly have a high value of the refractive index, which introduces large Fresnel losses. In the former case, thickness optimization seems to be a good solution to increase the efficiency of designed elements, while in the latter, antireflection coatings should be used to minimize the amount of wasted energy.

\section{References}

[1] J.-L. Coutaz, Optoélectronique térahertz (Les Ulis CEDEX A, France, EDP Sciences 2012).

[2] D. Headland, Y. Monnai, D. Abbott, C. Fumeaux, W. Withayachumnankul, APL Photonics 3, 5 (2018) https://doi.org/10.1063/1.5011063

[3] S.F. Busch, M. Weidenbach, M. Frey, F. Schäfer, T. Probst, M. Koch, Journal of Infrared, Millimeter, and Terahertz Waves 35, 12 (2014). https://doi:10.3390/ma11020189

[4] A. Siemion, P. Kostrowiecki-Lopata, A. Pindur, P. Zagrajek, M. Sypek, Adv. Mat. Scien. Eng. 2016, 9615698 (2016). http://dx.doi.org/10.1155/2016/9615698

[5] A. Siemion, A. Siemion, M. Makowski, J. Suszek, J. Bomba, A. Czerwinski, F. Garet, J.-L. Coutaz, M. Sypek, Opt. Lett. 37, 4320 (2012). https://doi.org/10.1364/OL.37.004320

[6] J.-L. Coutaz, F. Garet, E. Bonnet, A.V. Tishchenko, O. Parriaux, M. Nazarov, Acta Phys. Pol. A 107, 26 (2005). https://doi.org/10. 12693/aphyspola.107.26

[7] M.S. Heimbeck, P.J. Reardon, J. Callahan, H.O. Everitt, Opt. Lett. 35, 21 (2010). https://doi.org/10.1364/OL.35.003658

[8] D. Li, S. Shu, F. Li, G. Ma, Y. Dai, H. Ma, Opt. Comm. 284, 10 (2011). https://doi.org/10.1016/j.optcom.2011.01.015

[9] X. Li, S.F. Yu, IEEE J. Quant. Electr. 46, 6 (2010). https://doi.org/10. 1109/JQE.2010.2040805

[10] B. Nöhammer, C. David, J. Gobrecht, H.P. Herzig, Opt. Lett. 28(13), 1087 (2003). https://doi.org/10.1364/OL.28.001087

[11] V. Deuter, M. Grochowicz, S. Brose, J. Biller, S. Danylyuk, T. Taubner, D. Grutzmacher, L. Juschkin, Intern. Conf. on Extreme Ultraviolet Lithography 2018 10809, 108091A (2018). https://doi.org/10. $1117 / 12.2502879$

[12] J.W. Goodman, Introduction to Fourier optics (Greenwood Village, USA, Roberts \& Company Publishers 2005).

[13] W.B. Veldkamp, Appl. Opt. 21(17), 3209 (1982). https://doi.org/ 10.1364/OL.28.001087

[14] W.B. Veldkamp, C.J. Kastner, Appl. Opt. 21(2), 345 (1982). https:// doi.org/10.1364/AO.21.000345

[15] https://www.mcortechnologies.com/de/3d-drucker/mcor-iris/

[16] M. Sypek, M. Makowski, E. Hérault, A. Siemion, A. Siemion, J. Suszek, F. Garet, J.-L. Coutaz, Opt. Lett. 37, 12 (2012). https:// doi.org/10.1364/OL.37.002214 